\title{
Adherence to recommendations for cervical and breast cancer screening in systemic sclerosis
}

\author{
P. Caramaschi' ${ }^{1}$, D. Biasi' ${ }^{1}$ C. Caimmi', R. Vaccari², I. Dal Forno', \\ S. Pieropan ${ }^{1}$, S. Adami ${ }^{1}$ \\ ${ }^{1}$ Rheumatology Unit, Department of Medicine, University of Verona; \\ ${ }^{2}$ General practitioner, Verona, Italy
}

\begin{abstract}
SUMMARY
The aim of the study was to evaluate the adherence of systemic sclerosis (SSc) female patients to cervix and breast cancer screening procedures, as suggested by local guidelines.

A cohort of 84 SSc women was asked if they had undergone mammography and Pap test during the previous 2- and 3-year intervals, as indicated according to the Italian recommendations. The results were compared with those collected in patients affected by other chronic rheumatic disorders and in the general population.

More than $85 \%$ of SSc women declared to comply with an age-related cervix and breast cancer screening schedule. The data were similar to those collected in patients affected by other chronic rheumatic disorders, whereas the subjects belonging to the general population reported to undergo breast cancer screening more frequently. Among SSc women, neither the educational level, nor the lung and skin involvement influenced their cancer screening program compliance. Only a positive history of ischemic digital ulcers seemed to interfere with mammography.

Our study reported a very high percentage of SSc female patients who adhered to programs for the early detection of cervical and breast cancer. The significant adherence to guidelines may be due to the schedule adopted by the local health public service, which regularly invites eligible subjects by mail to undergo cancer screening at no charge.
\end{abstract}

Key words: Systemic sclerosis, Chronic rheumatic diseases, Cervical cancer screening, Breast cancer screening.

Reumatismo, 2014; 66 (4): 264-269

\section{INTRODUCTION}

n Italy, the current recommendations for the early diagnosis of the most frequent female cancers suggest screening women aged 25-64 years for cervical cancer with Papanicolaou (Pap) test at 3-year intervals and women aged 50-69 years at 2-year interval with mammography (1). The aim of cancer screening is to detect precancerous lesions or early neoplastic transformation, thereby resorting to earlier and potentially less invasive treatment than what is required for symptomatic and more advanced cancers. The benefit of cancer screening procedures in terms of lower incidence of the invasive disease and lower mortality has extensively been documented (2-5).

There are discordant data regarding adherence to cancer screening programs in patients affected by systemic lupus erythematosus (SLE). A Canadian study showed that 53\% of 48 SLE women aged 50-69 and $33 \%$ of 27 SLE women aged less than 30 years reported to have performed a mammogram and a Pap test, in the previous year. These figures compare with $74 \%$ and $56 \%$ of similarly aged control women, respectively. Moreover, among 51 SLE subjects aged 50 and older, only $18 \%$ reported screening for colorectal cancer compared to $48 \%$ in the general population. Non-white SLE patients, those with lower educational level, and with higher disease damage scores were less likely to undergo cervical Pap testing (6). It is not clear why SLE women are less careful in performing age-related cancer screening in agreement with recommendations. These results might be attributed to the tedious- 
ness of adhering to screening programs by patients who need to frequently perform medical examinations for the periodic assessment of their systemic disease. On the contrary, a more recent study performed in California reported that $70 \%$ of eligible SLE women underwent mammograms and Pap tests, in a similar percentage of control subjects and of patients with chronic nonrheumatic diseases (7). In keeping with the experience of Bernatsky et al. (6), it was observed that patients with lower educational attainment were less likely to undergo Pap tests. Similar data were collected in Italian SLE women concerning the adherence to cervical cancer screening; $66.4 \%$ of 140 patients declared to perform a Pap test at least every 3 years, as suggested by local guidelines, without significant difference in comparison with the general population (8). SLE women should be encouraged to regularly undergo Pap test considering that some studies reported a higher incidence of cervical dysplasia (9) and cervical cancer (10) in comparison with the general population. However, a recent review suggested that literature data are contrasting (11).

To the best of our knowledge there are no data concerning the adherence to recommendations for cervical and breast cancer screening in systemic sclerosis (SSc), a chronic systemic autoimmune disease, that, as SLE, may involve skin and visceral organs and that requires frequent examinations for follow up of the disease, early diagnosis of complications, and management of comorbidities.

The aim of the present study was to assess if SSc female patients underwent Pap test and mammography as suggested by current recommendations to the same extent of female patients suffering from other chronic rheumatic diseases and of the general population.

\section{MATERIALS AND METHODS}

\section{Study population}

Outpatient women affected by SSc aged 25-69 years followed at the Rheumatology Unit of Verona, Italy, were consecutively enrolled for the present study between January and June 2013. All patients fulfilled the American College of Rheumatology (ACR) criteria for the diagnosis of SSc (12). The distinction between limited and diffuse cutaneous SSc was made according to the criteria by LeRoy et al. (13).

All patients underwent clinical examination and laboratory evaluation including antinuclear and anti-extractable nuclear antigen antibody detection by indirect immunofluorescence on human epithelial cell line 2 cells and enzyme-linked immunosorbent assay method, respectively. Every year the patients underwent investigations in order to evaluate heart and lung involvement. Pulmonary fibrosis and pulmonary artery hypertension were diagnosed by high-resolution computed tomography and right heart catheterisation, respectively. Heart and gastrointestinal involvement was defined in agreement with Medsger's proposal (14). Skin involvement was assessed by modified Rodnan skin score (15). Digital ulcers were defined as ischemic ulcers located at the digit tip.

\section{Control subjects}

Patients affected by other chronic rheumatic disorders, which mainly affect female sex as SLE, rheumatoid arthritis, primary Sjögren's syndrome and fibromyalgia aged 25-69 years were consecutively enrolled as controls. The diseases were diagnosed in agreement with the most recent available criteria (16-19).

Moreover female subjects from the general population aged 25-69 years attending the office of a general practitioner were consecutively enrolled.

\section{Cervical and breast cancer screening}

During the periodic visits at the Rheumatology Unit, rheumatic patients aged 25-64 years were asked if they had undergone Pap test in the previous 3-year interval, except for patients previously hysterectomized. Female patients aged 50-69 years were asked if they had undergone mammography in the previous 2-year interval. A general practitioner asked the same questions to his female patients. 
Both patients and subjects from the general population were also interviewed concerning their educational status; we ranked subjects in low and high educational level depending on whether they attended school for $\leq 8$ or $>8$ years.

\section{Statistics}

Statistic workup was performed using SPSS 17.0 statistical package (SPSS Inc., Chicago, IL, USA). Population's characteristics are described as mean and standard deviation or median, as appropriate. The number of patients that underwent screening procedures was expressed as percentage. Differences between groups were calculated by t-test or Mann-Whitney test, according to the data characteristics. Differences of categorical variables between groups were analyzed by Fisher's exact test or Chi square test, as appropriate.

\section{RESULTS}

\section{Demographic and clinical features}

The cohort of SSc patients followed at the Rheumatology Unit of the University of Verona enrolled for the present study was composed of 84 subjects. Sixty-two patients were aged 25-64 years; after exclusion of 5 cases previously hysterectomized, the eligible patients for cervical cancer screening were 57 . Sixty patients aged 50 69 years were eligible for mammography; only one of these was previously treated with quadrantectomy for breast cancer. All the subjects were of Caucasian origin and all but 2 of Italian origin.

Table I reports the main demographic and clinical features of SSc cases.

\section{Cervical cancer screening}

The age of SSc patients who were recommended to undergo Pap test was not different in comparison with patients affected by other chronic rheumatic disorders and with the sample of the general population.

Eight out of 57 SSc patients $(14.0 \%)$ did not undergo the Pap test during the previous 3-year interval.

As to the other subgroups, 5 out of 103 pa-
Table I - Demographic and clinical characteristics of the 84 patients affected by systemic sclerosis.

\begin{tabular}{|l|l|}
\hline Age (years) $^{*}$ & $56.2(9.9)$ \\
\hline Disease duration (years) $^{*}$ & $10.3(5.8)$ \\
\hline $\begin{array}{l}\text { Disease pattern } \\
\text { Diffuse }\end{array}$ & $24(28.6 \%)$ \\
Limited $^{\circ}$ & $60(71.4 \%)$ \\
\hline Autoantibody pattern & \\
ACA positivity & $44(52.4 \%)$ \\
Anti-Scl70 positivity & $18(21.4 \%)$ \\
ANA positivity (absent ACA and & $22(26.2 \%)$ \\
anti-Scl70) $^{\circ}$ & \\
\hline Pulmonary fibrosis $^{\circ}$ & $17(20.2 \%)$ \\
\hline Pulmonary artery hypertension $^{\circ}$ & $1(1.2 \%)$ \\
\hline Heart involvement $^{\circ}$ & $31(36.9 \%)$ \\
\hline Gastrointestinal involvement $^{\circ}$ & $70(83.3 \%)$ \\
\hline Digital ulcers $^{\circ}$ & $21(25 \%)$ \\
\hline
\end{tabular}

${ }^{*}$ Values expressed as mean and standard deviation; ${ }^{\circ}$ values expressed as absolute number and percentages. ACA, anticentromere antibodies; Anti-Scl70, anti-Scl70 antibodies; ANA, antinuclear antibodies.

tients affected by other chronic rheumatic disorders $(4.9 \%)$ and 3 out of 81 controls of the general population $(3.7 \%)$ did not undergo Pap test during the previous 3-year interval.

The adherence to cervical cancer screening by SSc patients was not different in comparison with patients affected by other chronic rheumatic disorders and with the general population $(\mathrm{P}=0.066$ and $\mathrm{P}=0.051$, respectively).

These data are reported in table II.

\section{Breast cancer screening}

The age of SSc patients who were recommended to undergo Pap test was not different in comparison with patients affected by other chronic rheumatic disorders, whereas subjects from the general population were younger $(\mathrm{P}=0.002)$.

Eight out of 60 SSc patients $(13.3 \%)$ did not undergo mammography during the previous 2-year interval.

Concerning the other subgroups 3 out of 76 patients affected by other chronic rheumatic disorders $(4.9 \%)$ did not undergo mammography during the previous 2-year interval. Instead all controls of the general population reported to have regularly performed breast cancer screening.

The adherence to breast cancer screening 
Table II - Frequency of adherence to cervical and breast cancer screening among patients affected by systemic sclerosis, other chronic rheumatic disorders (rheumatic patient controls), and subjects from the general population.

\begin{tabular}{|l|l|l|l|l|}
\hline \multicolumn{2}{|l|}{ Yes } & No & Total & $\begin{array}{l}\text { Comparison between SSc pts } \\
\text { and other subgroups }\end{array}$ \\
\hline Cervical cancer screening & $49(86.0 \%)$ & $8(14.0 \%)$ & 57 & - \\
\hline SSc & $98(95.1 \%)$ & $5(4.9 \%)$ & 103 & $\mathrm{P}=0.066$ \\
\hline Rheumatic patient controls & $78(96.3 \%)$ & $3(3.7 \%)$ & 81 & $\mathrm{P}=0.051$ \\
\hline General population & \multicolumn{5}{|l|}{} \\
\hline Breast cancer screening & $52(86.7 \%)$ & $8(13.3 \%)$ & 60 & - \\
\hline SSc & $73(96.1 \%)$ & $3(3.9 \%)$ & 76 & $\mathrm{P}=0.060$ \\
\hline Rheumatic patient controls & $55(100 \%)$ & 0 & 55 & $\mathrm{P}=0.006$ \\
\hline General population &
\end{tabular}

SSc, systemic sclerosis; pts, patients.

by SSc patients was not different in comparison with patients affected by other chronic rheumatic disorders $(\mathrm{P}=0.060)$; on the contrary it was lower compared to that of the general population $(\mathrm{P}=0.006)$.

These data are reported in Table II.

\section{Educational level}

There was no difference in educational level between SSc patients who did and who did not perform cervical and breast cancer screening, as well as in patients affected by rheumatic diseases other than SSc and in the general population.

\section{Clinical features and cancer screening in systemic sclerosis}

There was no difference in SSc between patients who did and who did not perform cervical and breast cancer screening in relation to age, disease duration, pattern of disease, autoantibody profile, skin and lung involvement.

Patients with a positive history for digital ulcers tended to be less prone to perform breast cancer screening than those without $(\mathrm{P}=0.059)$ (Table III). On the contrary there was no difference regarding cervical cancer screening.

Table III - Frequency of adherence to cervical cancer and breast screening among patients affected by systemic sclerosis, accordingly to the presence or not of ischemic digital ulcers, pulmonary involvement and type of cutaneous subset.

\begin{tabular}{|c|c|c|c|c|c|}
\hline \multicolumn{2}{|l|}{ Digital ulcers } & Yes & No & Total & $\begin{array}{l}\text { Comparison between SSc } \\
\text { subgroups }\end{array}$ \\
\hline \multirow[t]{2}{*}{ Breast cancer screening } & Yes & $9(69.2 \%)$ & $43(91.5 \%)$ & 52 & \multirow[t]{2}{*}{$P=0.059$} \\
\hline & No & $4(30.8 \%)$ & $4(8.5 \%)$ & 8 & \\
\hline \multirow[t]{2}{*}{ Cervical cancer screening } & Yes & 14 (82.4\%) & $35(87.5 \%)$ & 49 & \multirow[t]{2}{*}{ n.s. } \\
\hline & No & $3(17.6 \%)$ & $5(12.5 \%)$ & 8 & \\
\hline \multicolumn{2}{|l|}{ Pulmonary involvement } & Yes & No & Total & $\begin{array}{l}\text { Comparison between SSc } \\
\text { subgroups }\end{array}$ \\
\hline \multirow[t]{2}{*}{ Breast cancer screening } & Yes & $12(80 \%)$ & $40(88.9 \%)$ & 52 & \multirow[t]{2}{*}{ n.s. } \\
\hline & No & $3(20 \%)$ & $5(11.1 \%)$ & 8 & \\
\hline \multirow[t]{2}{*}{ Cervical cancer screening } & Yes & $8(88.9 \%)$ & $41(83.7 \%)$ & 49 & \multirow[t]{2}{*}{ n.s. } \\
\hline & No & $1(11.1 \%)$ & $7(16.3 \%)$ & 8 & \\
\hline \multicolumn{2}{|l|}{ Diffuse subset } & Yes & No & Total & $\begin{array}{l}\text { Comparison between SSc } \\
\text { subgroups }\end{array}$ \\
\hline \multirow[t]{2}{*}{ Breast cancer screening } & Yes & $13(86.7 \%)$ & $39(88.6 \%)$ & 52 & \multirow[t]{2}{*}{ n.s. } \\
\hline & No & $3(13.3 \%)$ & $5(11.4 \%)$ & 8 & \\
\hline \multirow[t]{2}{*}{ Cervical cancer screening } & Yes & $14(87.5 \%)$ & $35(85.4 \%)$ & 49 & \multirow[t]{2}{*}{ n.s. } \\
\hline & No & $2(12.5 \%)$ & $6(14.6 \%)$ & 8 & \\
\hline
\end{tabular}

SSc, systemic sclerosis, n.s., not significant. 


\section{DISCUSSION}

AND CONCLUSIONS

Our study shows that the percentage of SSc female patients who adhere to programs for the early detection of cervical and breast cancer was high ( $>85 \%$ of the cases), even if the general population more frequently performed mammography. The elevated adherence to recommendations may be likely due to the organization of the local health public service, which regularly invites by mail eligible subjects to undergo cancer screening at no charge. The collected data were self-reported like in previous studies (6-8). This methodology is considered reasonable even if it may overestimate the adherence to screening procedures (20).

The adherence to screening programs was not influenced by the educational level, unlike what was reported in other studies in $\operatorname{SLE}(6,7)$. Moreover there was no difference comparing SSc cases with and without lung involvement as well in relation to the severity of the skin involvement, whereas patients with a positive history of ischemic digital ulcers tended to undergo mammography less frequently than patients who never suffered from this manifestation. In recent years the negative impact of digital ulcers on disability, the social and economic burden and the quality of life received great attention (21-24). This painful clinical manifestation may predispose to severe complications like soft tissue infections, osteomyelitis and gangrene.

The prevalence of pulmonary fibrosis and pulmonary artery hypertension in our SSc population was low. This may be due to many reasons, including the great heterogeneity of the disease and the design of the study, which led to exclude male patients and women older than 69 years. Male sex is associated with a more frequent interstitial lung disease (25) and late age at scleroderma onset is a risk factor for development of pulmonary artery hypertension (26).

No other reports were published regarding adherence to cervical and breast cancer screening in SSc. A previous Italian study on SLE patients showed that two thirds of eligible respondents regularly performed Pap test (8). A comparison with other experiences performed in other countries regarding age-related cancer screening procedures was not feasible on the grounds of the different local guidelines.

Recently, two meta-analyses were published about cancer incidence among SSc patients $(27,28)$. The relative risk to develop all invasive cancer was quantified in 1.75 (27). SSc men were more prone than women to develop neoplastic diseases (28). The results for selected cancers showed that SSc patients have in comparison with the general population a higher risk of developing lung and haematological neoplasms $(27,28)$, as well liver and bladder cancers (28). The incidence of breast cancer (27, 28) and cervix cancer (28) was not increased among SSc females in comparison with the general population, even if SSc women reported abnormal Pap test results more frequently than healthy controls (29). This indicates that SSc women should be pressed to undergo the age-related screening cancer programs recommended for the general population.

Our study showed that a high-quality prevention strategy for the early detection of the most frequent female cancers, like those implemented in our region, ensures a high level of adherence among a category of high-risk patients as those affected by SSc. We have seen that patients with severe complications, such as ischemic digital ulcers, are somewhat less prone to comply with breast cancer early detection strategies and this should prompt rheumatologists to devote greater attention to these patients.

\section{REFERENCES}

1. Ministero della Salute. Screening oncologici; 2006. Available from: http://www.ccmnetwork.it/documenti_Ccm/pubblicazioni/ Screening_oncologici.pdf

2. Quinn M, Babb P, Jones J, Allen E. Effect of screening on incidence of and mortality from cancer of cervix in England: evaluation based on routinely collected statistics. BMJ. 1999; 318: 904-8.

3. Peto J, Gilham C, Fletcher O, Matthews FE. The cervical cancer epidemic that screening 
has prevented in the UK. Lancet. 2004; 364: 249-56.

4. Anttila A, Nieminen P. Cervical cancer screening programme in Finland with an example on implementing alternative screening methods. Coll Antropol. 2007; 31: 17-22.

5. Nelson HD, Tyne K, Naik A, Bougatsos C, Chan BK, Humphrey L, et al. Screening for breast cancer: an update for the U.S. Preventive Services Task Force. Ann Intern Med. 2009; 151: 727-37.

6. Bernatsky SR, Cooper GS, Mill C, RamseyGoldman R, Clarke AE, Pineau CA. Cancer screening in patients with systemic lupus erythematosus. J Rheumatol. 2006; 33: 45-9.

7. Yazdany J, Tonner C, Trupin L, Panopalis P, Gillis JZ, Hersh AO, et al. Provision of preventive health care in systemic lupus erythematosus: data from a large observational cohort study. Arthritis Res Ther. 2010; 12: R84.

8. Tani C, Carli L, Mosca M, Baldini C, Consensi A, Doveri M, et al. Adherence to cervical cancer screening in an Italian SLE cohort. Reumatismo. 2011; 63: 11-7.

9. Bernatsky S, Kale M, Ramsey-Goldman R, Gordon C, Clarke AE. Systemic lupus and malignancies. Curr Opin Rheumatol. 2012; 24: 177-81.

10. Dey D, Kenu E, Isenberg DA. Cancer complicating systemic lupus erythematosus - a dichotomy emerging from a nested case-control study. Lupus. 2013; 22: 919-27.

11. Santana IU, Gomes Ado N, Lyrio LD, Rios Grassi MF, Santiago MB. Systemic lupus erythematosus, human papillomavirus infection, cervical pre-malignant and malignant lesions: a systematic review. Clin Rheumatol. 2011; 30: 665-72.

12. [No authots listed]. Preliminary criteria for the classification of systemic sclerosis (scleroderma). Subcommittee for scleroderma criteria of the American Rheumatism Association diagnostic and therapeutic criteria committee. Arthritis Rheum. 1980; 23: 581-90.

13. LeRoy EC, Black CM, Fleischmajer R, Jablonska S, Krieg T, Medsger TA Jr, et al. Scleroderma (systemic sclerosis): classification, subsets and pathogenesis. J Rheumatol. 1988; 15: 202-5.

14. Medsger TA Jr, Bombardieri S, Czirjak L, Scorza R, Della Rossa A, Bencivelli W. Assessment of disease severity and prognosis. Clin Exp Rheumatol. 2003; 21: S42-6.

15. Akesson A, Fiori G, Krieg T, van den Hoogen FHJ, Seibold JR. Assessment of skin, joint, tendon and muscle involvement. Clin Exp Rheumatol. 2002; 21: S5-8.

16. Tan EM, Cohen AS, Fries JF, Masi AT, McShane DJ, Rothfield NF, et al. The 1982 revised criteria for the classification of systemic lupus erythematosus. Arthritis Rheum. 1982; 25: 1271-7.
17. Arnett FC, Edworthy SM, Bloch DA, McShane DJ, Fries JF, Cooper NS, et al. The American Rheumatism Association 1987 revised criteria for the classification of rheumatoid arthritis. Arthritis Rheum. 1988; 31: 315-24.

18. Vitali C, Bombardieri S, Jonsson R, Moutsopoulos HM, Alexander EL, Carsons SE, et al. Classification criteria for Sjögren's syndrome: a revised version of the European criteria proposed by the American-European Consensus Group. Ann Rheum Dis. 2002; 61: 554-8.

19. Wolfe F, Clauw DJ, Fitzcharles MA, Goldenberg DL, Katz RS, Mease P, et al. The American College of Rheumatology preliminary diagnostic criteria for fibromyalgia and measurement of symptom severity. Arthritis Care Res. 2010; 62: 600-10.

20. Rauscher GH, Johnson TP, Cho YI, Walk AJ. Accuracy of self-reported cancer-screening histories: a meta-analysis. Cancer Epidemiol Biomarkers Prev. 2008; 17: 748-57.

21. Mouthon L, Mestre-Stanislas C, Bérezné A, Rannou F, Guilpain P, Revel M, et al. Impact of digital ulcers on disability and health-related quality of life in systemic sclerosis. Ann Rheum Dis. 2010; 69: 214-7.

22. Nihtyanova SI, Brough GM, Balck CM, Denton CP. Clinical burden of digital vasculopathy in limited and diffuse cutaneous systemic sclerosis. Ann Rheum Dis 2008; 67: 120-3.

23. Guillevin L, Hunsche E, Denton CP, Krieg T, Schwierin B, Rosenberg D, et al. Functional impairment of systemic scleroderma patients with digital ulcerations: results from the DUO Registry. Clin Exp Rheumatol. 2013; 31: 7180 .

24. Cozzi F, Tiso F, Lopatriello S, Ciprian L, Sfriso $\mathrm{P}, \mathrm{Berto} \mathrm{P}$, et al. The social costs of digital ulcer management in sclerodema patients: an observational Italian pilot study. Joint Bone Spine. 2010; 77: 83-4.

25. Hussein H, Lee P, Chau C, Johnson SR. The effect of male sex on survival in systemic sclerosis. J Rheumatol. 2014; 41: 2193-200.

26. Schachna L, Wigley FM, Chang B, White B, Wise RA, Gelber AC. Age and risk of pulmonary arterial hypertension in scleroderma. Chest. 2003; 124: 2098-104.

27. Bonifazi M, Tramacere I, Pomponio G, Gabrielli B, Avvedimento EV, La Vecchia C, et al. Systemic sclerosis (scleroderma) and cancer risk: systematic review and meta-analysis of observational studies. Rheumatology. 2013; 52: 143-54.

28. Onishi A, Sugiyama D, Kumagai S, Morinobu A. Cancer incidence in systemic sclerosis: meta-analysis of population-based cohort studies. Arthritis Rheum. 2013; 65: 1913-21.

29. Bernatsky S, Hudson M, Pope J. Reports of abnormal cervical cancer screening tests in systemic sclerosis. Rheumatology. 2009; 48: 149-51. 